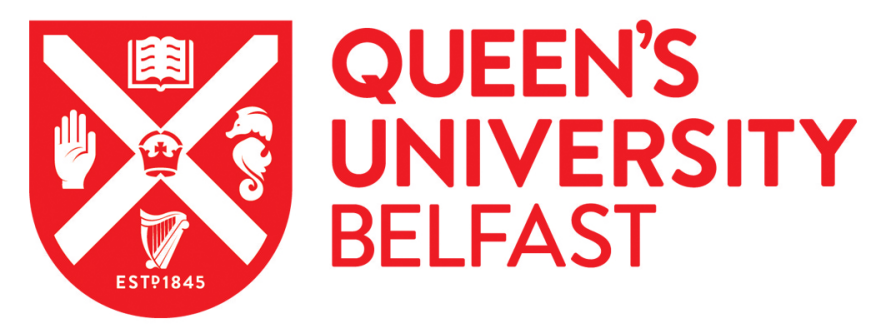

\title{
The effect of long term weathering on hemp and rapeseed concrete
}

Sheridan, J., Sonebi, M., Taylor, S., \& Amziane, S. (2020). The effect of long term weathering on hemp and rapeseed concrete. Cement and Concrete Research, 131, [106014]. https://doi.org/10.1016/j.cemconres.2020.106014

\section{Published in:}

Cement and Concrete Research

\section{Document Version:}

Publisher's PDF, also known as Version of record

\section{Queen's University Belfast - Research Portal:}

Link to publication record in Queen's University Belfast Research Portal

\section{Publisher rights}

(C) 2020 Elsevier Ltd.

This manuscript is distributed under a Creative Commons Attribution-NonCommercial-NoDerivs License

(https://creativecommons.org/licenses/by-nc-nd/4.0/), which permits distribution and reproduction for non-commercial purposes, provided the author and source are cited.

\section{General rights}

Copyright for the publications made accessible via the Queen's University Belfast Research Portal is retained by the author(s) and / or other copyright owners and it is a condition of accessing these publications that users recognise and abide by the legal requirements associated with these rights.

Take down policy

The Research Portal is Queen's institutional repository that provides access to Queen's research output. Every effort has been made to ensure that content in the Research Portal does not infringe any person's rights, or applicable UK laws. If you discover content in the Research Portal that you believe breaches copyright or violates any law, please contact openaccess@qub.ac.uk. 


\title{
The effect of long term weathering on hemp and rapeseed concrete
}

\author{
Joseph Sheridan ${ }^{1 *}$, Mohammed Sonebi ${ }^{1}$, Su Taylor ${ }^{1}$, Sofiane Amziane ${ }^{2}$ \\ 1Queen's University Belfast, School of Natural and Built Environment, Belfast, BT7 1NN, UK \\ ${ }^{2}$ Université Blaise Pascal, Institut Pascal, Polytech Clermont-Ferrand, 63174, Aubière, France \\ *Corresponding author; e-mail: jsheridan08@qub.ac.uk
}

\begin{abstract}
Two vegetal aggregate types are studied for their performance regarding immersion and outdoor weathering. The most widely researched bio-aggregate to date is hemp shiv; which is used in this study as well as chopped rapeseed straw which is an alternative bio-aggregate widely available in the UK. In this study the binder used is Vicat prompt natural cement as well as a viscosity modifying agent (VMA) admixture. It was found that the hemp aggregate produced the most durable concrete when compared to rapeseed, and the addition of a VMA resulted in a much more durable material for both aggregate types. Organic and inorganic leaching was also investigated, and it was found that the binder and soluble organics were leaching from all of the concrete types.
\end{abstract}

\section{Keywords}

Hemp; rapeseed straw; VMA; weathering; leaching 


\section{Introduction}

In recent decades subjects such as sustainability, carbon footprint and pollution are issues that have become increasingly important and well known to people on a global scale. It is widely recognised that the human race is required to revise its stance on these issues as industry, construction, energy and transport cause degradation to the environment and the planet as a whole. Thus, sustainability has a necessary focus in research across the globe.

Concrete is the second most consumed resource by the human race after water [1] and the construction sector as a whole is an industry with a vast carbon footprint. Indeed, the production of cement alone accounts for $5 \%$ of the entire world's $\mathrm{CO}_{2}$ output according to The Cement Sustainability Initiative [2], or 7\% according to Malhotra [3]. This prediction is based on the fact that 1 tonne of cement produced results in 1 tonne of $\mathrm{CO}_{2}$ released into the atmosphere [4]. The International Energy Agency (IEA) reported that $4.1 \mathrm{Gt}$ of cement was produced in 2017, resulting in $4.1 \mathrm{Gt}$ of $\mathrm{CO}_{2}$ emissions and the consumption of $10.5 \mathrm{Ej}$ of energy [5].

The data presented in the previous paragraph, along with the additional fact that energy consumption within the building sector needs to be reduced, has led to a focus in research on more sustainable building materials. Energy use within buildings can be greatly reduced simply by better insulation. It is reported by Eurostat [6] that $25.7 \%$ of all energy used in the European Union in 2013 was in households, slightly ahead of industry (25\%) and behind only transport (33.2\%). It is reported by the UK Department of Energy \& Climate Change that in the UK the amount of household energy that is used in heating space amounted to $62 \%$ [7]. Based on these figures roughly $15.9 \%$ of all energy used was in the heating of space. This is a number that has potential to be reduced by the use of new and improved building materials that are both sustainable to produce and also provide excellent levels of insulation. Both of these energy sectors need to be improved, and their carbon footprint reduced if the EU is to attain its global emissions targets of a reduction in greenhouse gas emissions of $40 \%$ for 2030 and $80 \%$ for horizon 2050 compared to the 1990 level.

One such material type that has the potential to achieve both of these targets is vegetal concretes. Considerable research has been conducted into bio-based building materials; however, the long-term durability of vegetal concretes is something that still needs to be investigated in depth. Several durability mechanisms have been studied thus far; from biological aging [8], [9], fire exposure [10], wetting and drying with variable humidity cycles [9], [11], carbonation [12], [13], salt exposure and freeze-thaw [14].

Limited studies have also been conducted on immersion weathering [15]-[18] however, more research is needed. Despite the mentioned investigations being a good start, the total experiment 
length, as well as the actual cycle lengths are not long enough to adequately investigate the effect of immersion weathering of vegetal concretes.

Leaching of vegetal aggregates is also investigated in this paper due to its obvious link to the immersion weathering mechanism. It is known that particular constituent parts of a plant's chemical makeup are soluble, such as hemicellulose [19] and lignin [20]. It has also been highlighted by Sedan et al. [21], [22] that pectin has the ability to be problematic in a cementitious matrix. This is because they have an affinity for calcium ions and react with them to form a non-reactive gel. If pectin is reacting with calcium ions then those ions are not available for hydration, leading to a retarding effect in the concrete's strength development. Thus, the leaching of pectin will be closely monitored in the leaching experiment.

The aim of this paper is to investigate the long-term weathering resistance of hemp and rapeseed concrete. This will be accomplished by firstly evaluating the resistance of the vegetal concretes to full immersion weathering using changes in mass, cross-section and compressive strength as testing parameters. Following this, the same parameters will be used to investigate the effect of long-term outdoor weathering under natural conditions. Finally, the organic and inorganic leaching of the vegetal concretes will be investigated by measuring the amount of organic material and calcium content of the leaching experiment testing water. The mixes used in this investigation were developed in a previous investigation by Sheridan et al. [23] and so a polyacrylic acid admixture is also used and its resistance to long term immersion weathering will be studied.

\section{Methodology}

\subsection{Materials}

The two aggregates that were used in this investigation were hemp shiv grown and packed in Driffield, East Yorkshire in the UK, and chopped rapeseed straw that was chopped and packed in County Kildare in Ireland (Figure 2.1). These aggregates were characterized in detail in an investigation conducted by Sheridan et al. [23]and so will not be repeated here, however it was found that the hemp aggregate used in this investigation was found to be larger, denser and more circular than the rapeseed aggregate. The hemp aggregate also absorbed less water (around $40 \%$ by mass after 24 hours of immersion). X-Ray tomography images are included in Figure 2.1 to illustrate the differences in the makeup of the two aggregates. There are clear and large vertical pores on the top face of the hemp stalk, and these are the pores that would carry water and nutrients further up the plant when it was alive. The composition is slightly different with the rapeseed straw, as it can be seen that although there are still vertical pores in the woody part of the straw, the main water absorption would come from the pithy part of what would be the inside of the straw. The binder that was used was Vicat 


\section{.}

prompt natural cement which is mined from a seam of argillaceous limestone in Grenobles, France. Finally, the VMA was a polyacrylic acid and was produced by Larsen Building Products in Belfast, Northern Ireland.

.
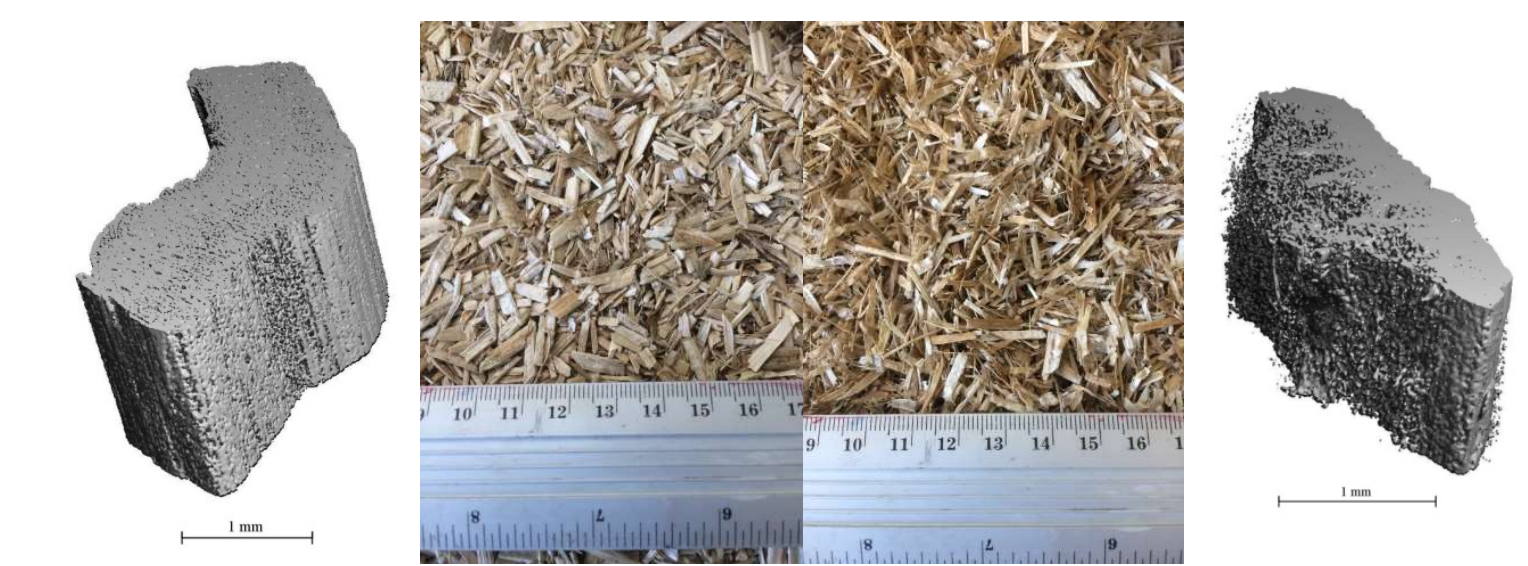

Figure 2.1 - Photograph and X-Ray tomography image of aggregates used in this investigation, hemp shiv (left) and rapeseed straw (right)

\subsection{Mixing, Casting and Curing Procedure}

The mechanical properties of the mix were investigated, and the properties chosen were the compressive strength and elastic modulus. The compressive strength of the samples was determined using $50 \mathrm{~mm}$ cubes and an accurately calibrated static materials testing machine with a $100 \mathrm{kN}$ load cell.

All of the samples in this investigation used the same aggregate:binder:water ratio, which was 1:2:3 by mass and resulted in a dry mix. This composition was chosen as it is the "wall" formulation in the professional regulations given by SEBTP [24], which published guidelines (in French. The samples were all cast using the same procedure, which was to add the aggregate and $65 \%$ of the mixing water to the mixing bowl first and mix for 2 minutes and 30 seconds. The binder was then added and mixed for a further 30 seconds before the remaining $35 \%$ of the mixing water and the chemical admixture (if one was used) was added. The amount of VMA added to the mixture was dictated by the amount of water as the ratio of water to VMA was 10:1 by mass. Mixing was conducted for a further 2 minutes to achieve homogeneity with a total mixing time of 5 minutes. The composition by mass of the mixes used in this investigation can be found in Table 2.1.

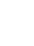


Table 2.1 - Mixture composition of all mixes in this investigation by mass (\%)

\begin{tabular}{|l|l|l|l|l|l|}
\hline & Hemp & Rapeseed & Vicat & VMA & Water \\
\hline Hemp Untreated & 17 & - & 33 & - & 50 \\
\hline Hemp VMA & 16 & - & 32 & 5 & 47 \\
\hline Rapeseed Untreated & - & 16 & 33 & - & 50 \\
\hline Rapeseed VMA & - & 16 & 32 & 5 & 47 \\
\hline
\end{tabular}

\section{Experimental Procedure}

\subsection{Compressive Strength}

Three $50 \mathrm{~mm}^{3}$ samples were again used for the purpose of repeatability and the method used was as follows:

1. Weigh the sample and measure the height, width and thickness to be able to calculate the density.

2. Position the sample in the Zwick machine and lower the crosshead until the compression pad is in contact with the top surface of the sample.

3. The loading rate was set to $0.6 \mathrm{~N} / \mathrm{s}$ and the samples were tested up to $20 \%$ strain. The compressive strength of the sample was also noted at $5 \%$ strain for the purposes of serviceability limits.

\subsection{Immersion Weathering Testing}

\section{Cycle Lengths}

In order to evaluate the immersion weathering resistance of hemp and rapeseed straw concrete a test was devised to investigate this property in the long term. The proposed method was an accelerated immersion weathering process which involved submerging the $100 \mathrm{~mm}$ cube samples in water to fully saturate them, then to desaturate them and dry them completely. These two processes formed a single cycle and these cycles were repeated numerous times in order to investigate long term durability. It was understood that, given the application of this mix design as a wall panel, this test could be considered extreme, and would only be observed in reality during cases of flooding. However, flooding is an intermittent concern in the U.K. and so it was decided that the most extreme case would be investigated.

Initially the saturation and desaturation times had to be established in order to form the cycle lengths. To do this the samples were submerged in water and each day were weighed after being placed on a steel grid for 30 mins to allow any free water to escape. If the mass of the sample was within $0.1 \%$ of the previous days mass, then full saturation was assumed to have been reached and the previous day was taken to be the length of that wetting cycle. Similarly, for drying, the samples 
were placed in an oven at $50^{\circ} \mathrm{C}$ and were weighed daily until desaturation had been reached and the length of the cycle found. This was carried out for each of the four mixes (untreated hemp, hemp VMA, untreated rapeseed, rapeseed VMA), all using the Vicat binder. The cycle lengths were found to be 11 days for both hemp and rapeseed untreated ( 5 days wetting and 6 days drying) and 13 days for hemp and rapeseed VMA ( 7 days wetting and 6 days drying). It was decided that the test would be a long-term test; 20 cycles were conducted meaning a total test time of 220 days for untreated samples and 260 days for VMA samples.

\section{Immersion Weathering Test}

Large plastic boxes were used and filled with water to submerge the samples (Figure 3.1) and the cycles were conducted in laboratory conditions according to the description given in section 3.2.1.

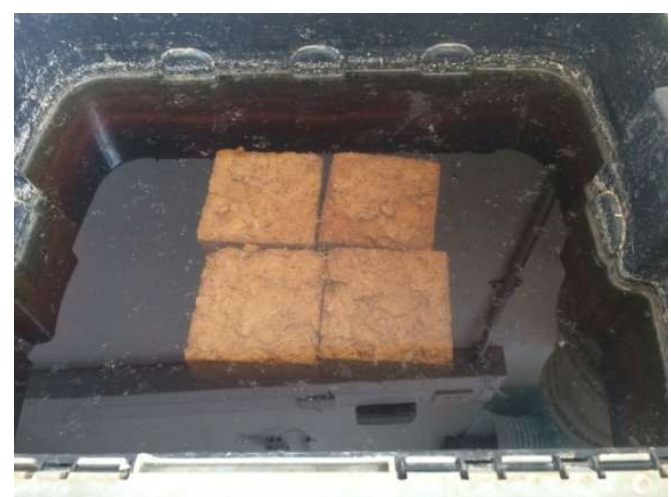

Figure 3.1 - Rapeseed VMA samples during an immersion weathering test

After each cycle had been completed the samples were weighed and measured for height, width and depth using digital callipers. The width and depth measurements were then plotted and analysed for sample swelling and shrinkage. This was done after the samples had been removed from the oven as well as removed from the water in order to measure any effect of the saturation/desaturation cycles, in particular swelling. Any changes in amount of water absorbed were also noted by observing the differences in mass of the samples. In order to investigate the effect that the submersion had caused after 5, 10, 15 and 20 cycles, samples were removed for compressive strength testing as well as Fourier-transfer infrared spectroscopy (FTIR) on the fibres.

\section{Outdoor samples}

The final phase of the weathering testing was to assess the effect, if any, of leaving samples outdoors to naturally weather for a year. Four samples of the same four mixes were left in an outdoor exposed environment for a year and then subsequently tested. Over the course of the year the 
samples were exposed to all kinds of weather systems including heavy rain, snow and heat and the average weather statistics for Northern Ireland from the Met Office can be seen in Table 3.1.

Table 3.1 - Weather statistics for Northern Ireland during the outdoor testing [25]

\begin{tabular}{|l|r|r|r|r|r|r|r|r|r|r|r|r|}
\cline { 2 - 12 } \multicolumn{1}{l|}{} & Oct-17 & $\begin{array}{r}\text { Nov- } \\
17\end{array}$ & $\begin{array}{r}\text { Dec- } \\
17\end{array}$ & $\begin{array}{r}\text { Jan- } \\
18\end{array}$ & $\begin{array}{r}\text { Feb- } \\
18\end{array}$ & $\begin{array}{r}\text { Mar } \\
-18\end{array}$ & $\begin{array}{r}\text { Apr- } \\
18\end{array}$ & $\begin{array}{r}\text { May- } \\
18\end{array}$ & $\begin{array}{r}\text { Jun- } \\
18\end{array}$ & $\begin{array}{r}\text { Jul- } \\
18\end{array}$ & $\begin{array}{r}\text { Aug- } \\
18\end{array}$ & $\begin{array}{r}\text { Sep- } \\
18\end{array}$ \\
\hline $\begin{array}{l}\text { Mean Temp } \\
\left({ }^{\circ} \mathrm{C}\right)\end{array}$ & 10.8 & 5.8 & 4.7 & 3.9 & 2.9 & 3.9 & 7.9 & 11.8 & 14.9 & $\begin{array}{r}15 . \\
8\end{array}$ & 14.4 & 11.5 \\
\hline Rainfall (mm) & 105.7 & 112.8 & 116.1 & 170.9 & 74 & 85.8 & 80.9 & 58.3 & 49.1 & 6 & 102 & 57 \\
\hline $\begin{array}{l}\text { Raindays } \geq 1 \\
\text { mm }\end{array}$ & 16.5 & 19.1 & 18.1 & 22.1 & 14.1 & 14.4 & 16.1 & 9.9 & 6.9 & 9.7 & 18.7 & 13.7 \\
\hline $\begin{array}{l}\text { Days of Air } \\
\text { Frost }\end{array}$ & 0.3 & 3.4 & 9 & 8.3 & 13.3 & 11 & 3.8 & 0.6 & 0 & 0 & 0 & 0.4 \\
\hline
\end{tabular}

201

The outdoor samples were placed, unfixed, on a simple platform adapted from a wooden pallet, and partially protected from factors such as high winds using a polymer-based mesh (Figure 3.2). Holes were cut into the mesh around the samples to allow for maximum exposure to solid or semi-solid systems such as snow. It should be noted that in a real-world application the material would be fully exposed to the things such as wind, which the polymer mesh partially protected against. However, this protection was only devised as a restraint, not a fixing, as the material was light enough to be blown off the platform during the year of testing had the restraint not been there. The cutting of the mesh was assumed to expose the material to any possible abrasion that would have been caused by the wind. The pallet was then lifted on to a shipping container outside the rear door of the laboratory to gain maximum exposure to the elements and also to avoid unwitting interference for the duration of the year.

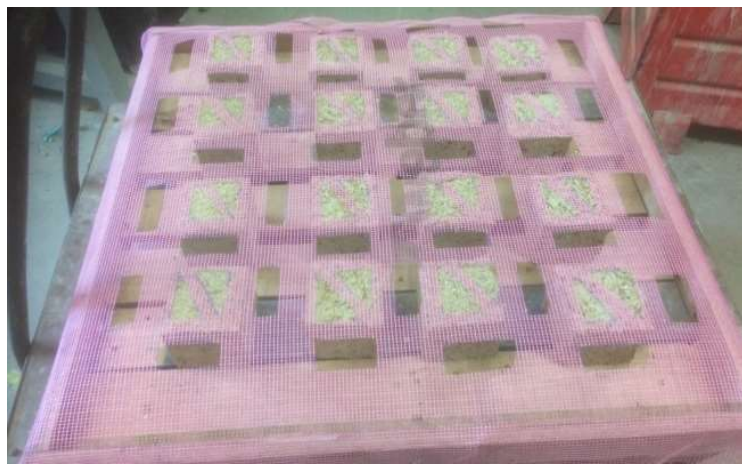

Figure 3.2-Outdoor samples prior to testing

In order to evaluate the effect of the weathering conditions in Northern Ireland on the samples they were tested for compressive strength as well as microstructure. The microstructure of 
the samples was analysed using scanning electron microscopy (SEM) and finally the fibres themselves were investigated using FTIR.

\subsection{Scanning Electron Microscopy}

In order to prepare the samples for SEM, they were first cut down to an appropriate size of around $50 \mathrm{~mm} \times 50 \mathrm{~mm} \times 50 \mathrm{~mm}$ using the mini saw and then fully impregnated with resin. Then the samples were allowed to cure for 48 hours before being polished with isopropanol and a $3 \mathrm{~mm}$ diamond polisher followed by a 1-micron diamond polisher. This was done to produce an extremely smooth surface to allow for clear and precise imaging under the electron microscope. The samples were then investigated under an FEI Quanta Scanning Electron Microscope.

\subsection{Fourier-transform infrared spectroscopy (FTIR)}

FTIR was used in conjunction with attenuated total reflectance (ATR) in order to analyse and quantify the constituent parts of the bio-aggregates before and after the experiments were conducted. The analysis was completed using a Jasco FT/IR-4100 FTIR machine (Figure 3.3) and was done by studying the vibratory sequences of the samples. The range of vibrations analysed was $650-$ $4000 \mathrm{~cm}^{-1}$ using a $4 \mathrm{~cm}^{-1}$ scan resolution.

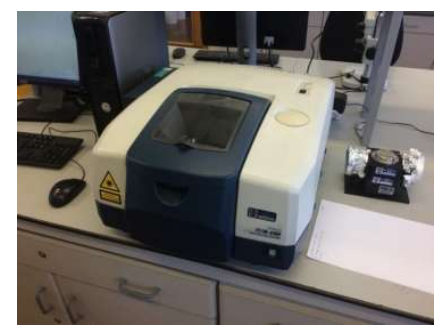

Figure 3.3 - Jasco FT/IR-4100 machine

\section{Results and Discussion}

\subsection{Immersion Weathering}

This section investigates the impact of the aggregate types and the addition of VMA and compares the effects of the tests on the compressive strength of the bio-concretes and chemical composition of the bio-aggregate. The swelling and the mass of the concrete samples were also recorded after every cycle of immersion weathering and the impacts of the above-mentioned variables on these parameters are discussed. 


\section{Mass gain}

The immersion weathering test was conducted over a period of 9 months (depending on the cycle lengths discussed in section 3.2.1). The changes in mass were recorded as the tests progressed and the comparative results for the aggregate types are presented in Figure 4.1. It should be noted that the mixes are denoted as follows: $\mathrm{RU}=$ rapeseed untreated, $\mathrm{HU}=$ hemp untreated, $\mathrm{RV}=$ rapeseed VMA and HV = hemp VMA.

As can be seen for both cases (untreated and with the VMA additive) the results are very close. As a percentage of the original mass recorded at the start of the test the hemp samples initially seemed to gain the most mass however towards the end of the test the rapeseed samples began to absorb similar amounts of water and indeed for the untreated samples gained more mass consistently from roughly cycle 12 onwards. This can be explained using the scanning electron microscopy images that were taken of the samples after the test had concluded at 20 cycles (Figure 4.2).

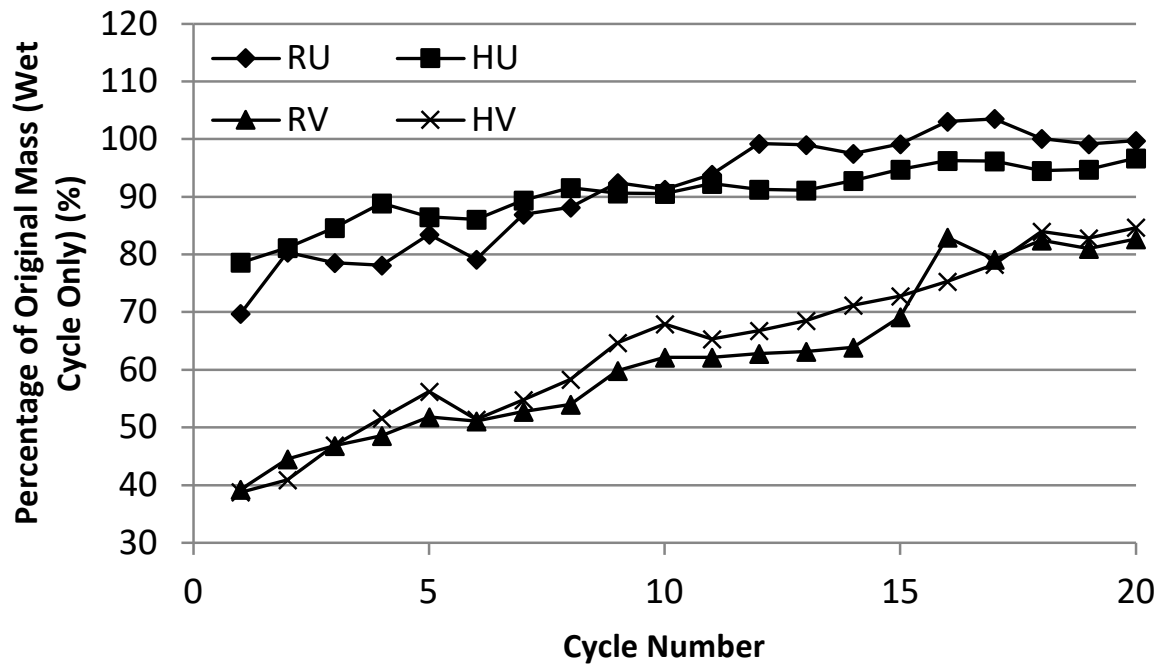

Figure 4.1 - The effect of aggregate type on mass change per cycle over time with regards to immersion weathering

Figure 4.2 illustrates the differences in the microstructure of the two concrete types (hemp untreated and rapeseed untreated). It can be seen that considerable damage has been caused to the microstructure and a lot of the binder has been washed away in both cases, however this effect is more severe for the rapeseed samples. At this stage the reason for this is unknown, and is something that should be studied further. However, it could be because of the fact that the rapeseed aggregate was smaller and more elongated when compared to the hemp aggregate [23]. The more elongated the aggregate, the more likely it is that the particles will be cast in a perpendicular orientation to the casting direction, creating anisotropy. If the aggregate is more circular (as the hemp was [23]), then 
297

Void either side of shiv

301 Aggregate

Void

all of the particles are less likely to be cast in a uniform direction. And if the particles are all orientated in different directions, then the matrix and the pore orientation would be messier and it would be much more difficult to extract the binder particles from the matrix.

\section{Binder}
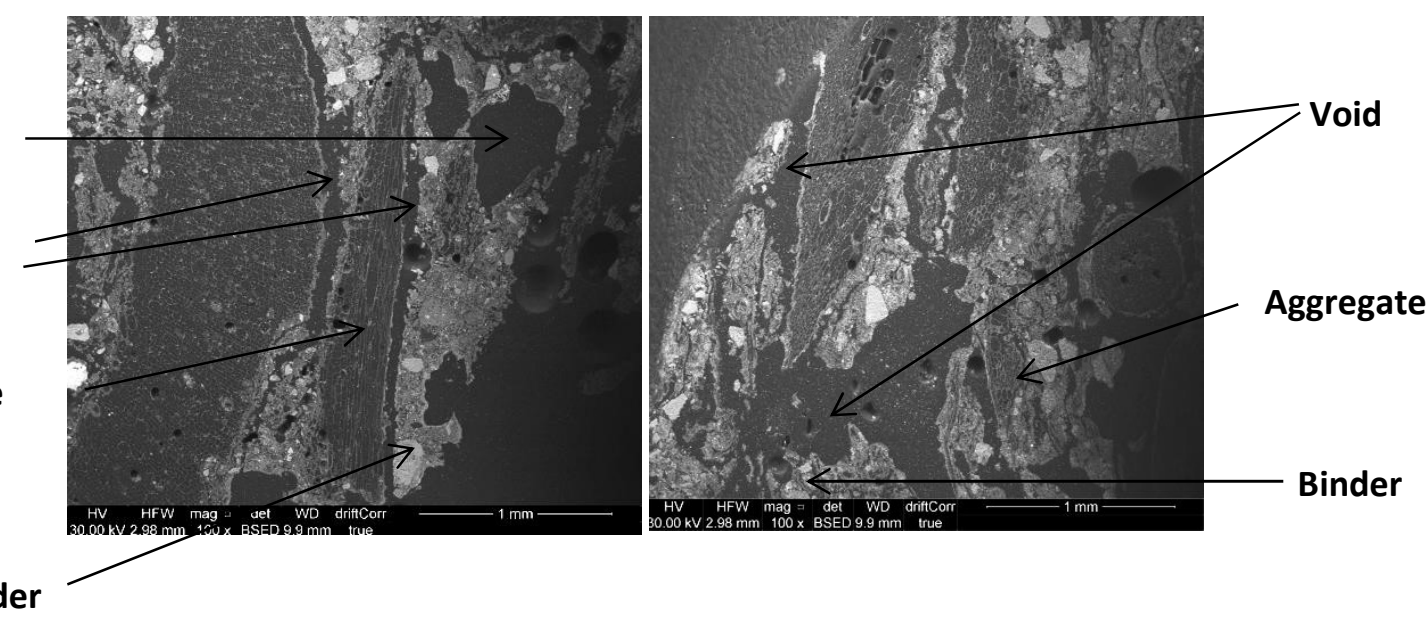

Figure 4.2 - SEM images of untreated hemp (left) and untreated rapeseed (right) samples after the immersion weathering test had concluded

Figure 4.2 has been annotated to illustrate the different components that were studied. It can be seen that the untreated hemp mix shows clear signs of damage with a large void in between the two shiv particles and another considerable void along the other side of the smaller piece of hemp. There are also voids exhibited within the mineral binder matrix in the image yet this loss of binder is nowhere near as severe as in the rapeseed image.

In Figure 4.2 (rapeseed) there is again a large amount of evidence of voids appearing near the aggregate; weakening the interfacial transition zone (ITZ). In addition to this a large amount of binder appears to have been washed away in the bottom left corner of the image.

The evidence of these voids explains the larger relative rise in mass gained of the rapeseed samples compared to the hemp samples. As the pores in the concrete matrix are widened due to cracking or binder being washed away, the porosity increased which allowed more space to be filled by water during the immersion weathering test.

The effect of the VMA on both of the aggregate types was also compared, comparing each aggregate type both with and without the VMA. For both aggregate types it is clear that the use of a VMA reduced the amount of mass gained. This is due to the VMA greatly increasing the density of vegetal concretes and so reducing the porosity, as was reported by Sheridan et al. [23]. This reduction in porosity would mean that there would be a reduced area of voids to be filled with water during the saturation part of the immersion cycle (and so less water absorption. This reduction in water 
absorption is reflected in the mass gained data (Figure 4.1) as the mass of the VMA samples is consistently lower than the untreated samples. However, it should be noted that in both cases the

327 VMA samples gained weight at a much faster rate than the untreated samples as the test progressed.

328 A conclusion that could be drawn is that the VMA samples are more susceptible to the pore widening 329 effect discussed in the previous paragraphs (binder washing away and void propagation), although the 330 precise reason for this is unclear and is something that should be studied further. This is supported by 331 the SEM imaging that was conducted on the samples. Figure 4.3 shows a comparison of all the mixes 332 after the immersion weathering testing had concluded with all of the 28-day control samples of the 333 mixes.

334

335
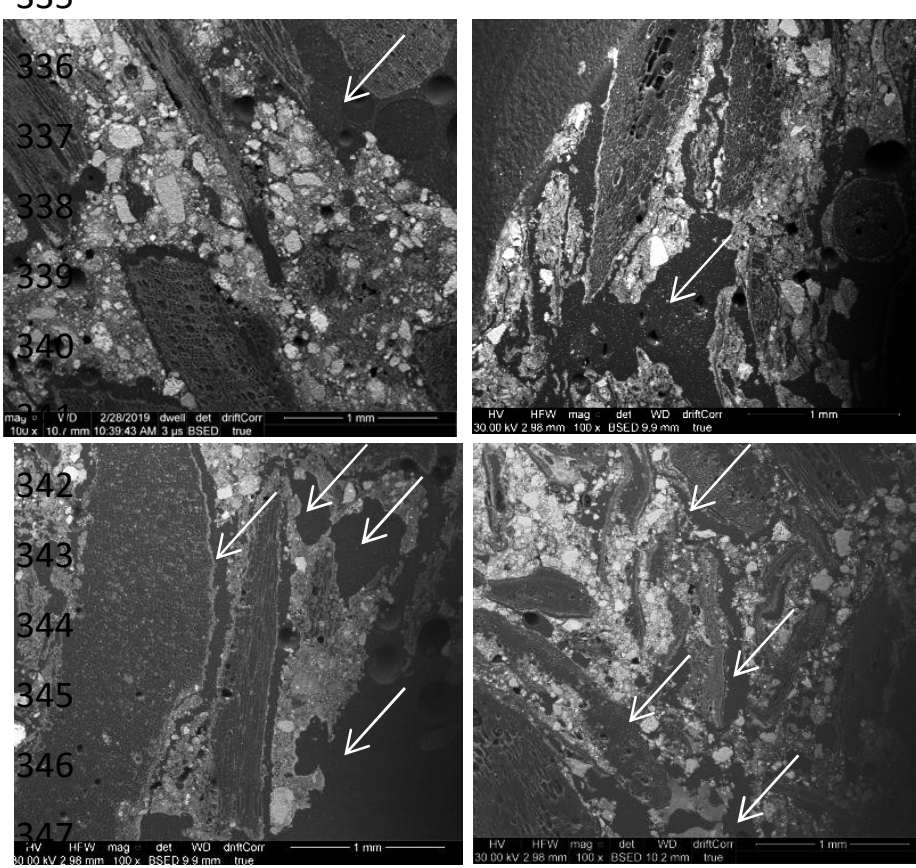

RU
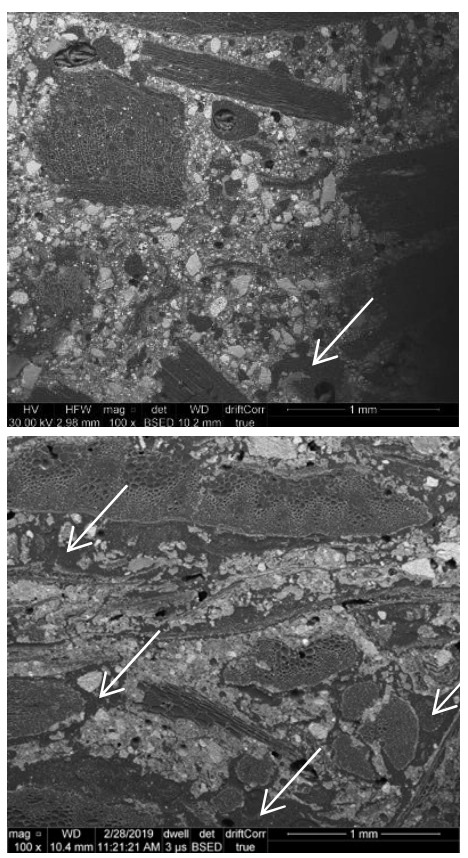

RV
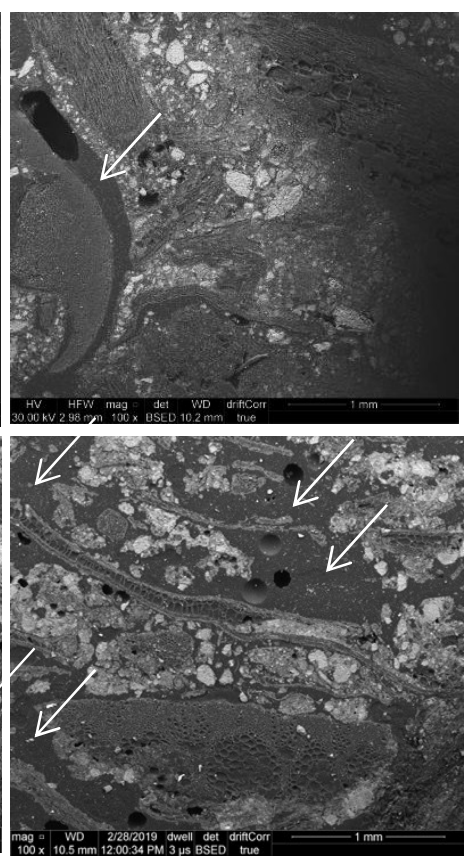

348

Figure 4.3 - SEM imaging of 28-day control samples (top line) and mixes after 20 cycles of the

Figure 4.3 illustrates that despite the fact that the untreated samples were heavily affected by the immersion weathering test with clear evidence of loss of binder or "inorganic leaching", crack propagation and pore widening the VMA samples are affected more severely (voids denoted with white arrows). This effect is probably observed because the initial strengthening and improvement in the vegetal concrete's ITZ [26] makes severe loss and damage possible. In the untreated sample the ITZ is already of low quality and high porosity is observed (Figure 4.3), and the scope for further damage is limited. However, sample failure is a more considerable threat and indeed was observed 
towards the end of the experiment in some of the untreated samples (discussed in the next section). Conversely the structure of the VMA samples by the end of the experiment was still sound, and is analogous to the VMA samples degrading throughout the experiment to a similar state to that in which the untreated samples started. That is to say the addition of the VMA reduced the porosity of the material but also gave scope for degradation; throughout the VMA immersion weathering tests the porosity of the samples slowly increased and returned to almost the initial levels of the untreated samples. This is reflected in the mass gain results as initially the VMA samples absorbed much less water than the untreated samples. However, during the duration of the experiment the amount of water absorbed rises until the VMA samples are absorbing almost as much water as the untreated samples. On the other hand, the amount of water the untreated samples absorb did not change as much; absorbing lots at the beginning of the experiment and also lots at the end.

\section{Sample swelling}

In addition to noting the mass of each sample before every wetting and drying cycle, the volume was measured. Presented are the results of the changes in cross-sectional area of the samples as the test progressed. It should be noted the results in the $z$ axis are not presented as the top of the sample was not flat and it was the exposed face during casting. This made the height an unreliable measurement as it varied slightly across the sample. Thus, the swelling was considered for the flatedged cross-sectional area only.

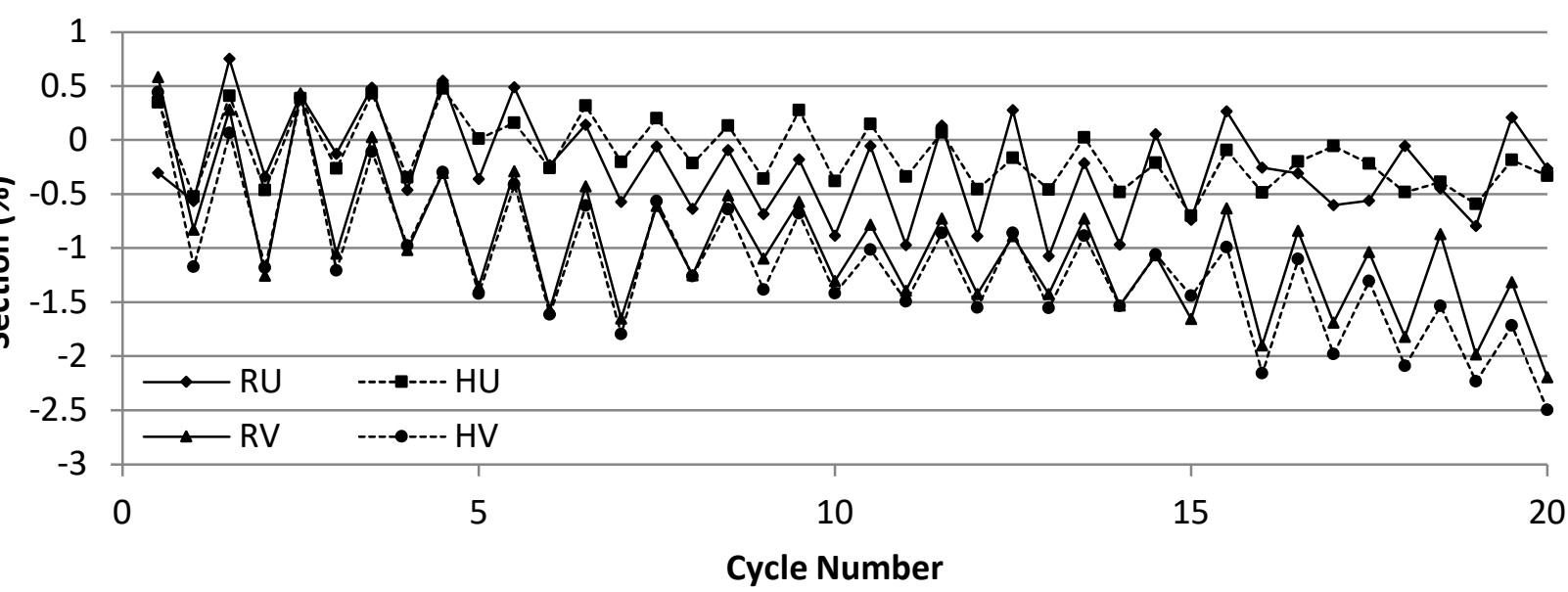

Figure 4.4 - Effect of VMA and aggregate type on cross-sectional swelling of concrete samples

Figure 4.4 shows the cross-sectional changes due to immersion weathering over time. The first thing to notice is that overall all the sample mixes lost area. Even if the changes were only small (in the range of $0.25-2.5 \%$ which is equal to $25-250 \mathrm{~mm}^{2}$ ) for a $100 \mathrm{~mm}$ cube, when scaled up to a real-life application of a house, a problem could arise. It is conceivable that an element of any of the 
studied samples could be fixed or glued between two other elements and shrinking like this could cause the build-up of internal stresses as the element shrinks and tries to pull away from its fixings. This potential concern would be more considerable for the VMA samples compared to the untreated samples, as the VMA samples' area reduced more. Although it should be kept in mind that this $2.5 \%$ loss of area was the end product of an extreme test over a long period of time with a high severity, therefore the seriousness of this concern could potentially be studied further and adjusted accordingly.

It can be seen that differences between the two aggregate types was relatively small, but the rapeseed samples shrank less than the hemp samples in both the untreated and VMA mixes. Finally, it can be seen that towards the end of the test the untreated samples started to become extremely soft, which impacted the swelling measurements. From cycle 16 onwards the defined structure of swelling during the wetting stage and shrinkage during the drying stage was lost, or at least was much less defined. In contrast the swelling and contraction remained throughout the end of the test for the VMA samples, also partially illustrating their partial resistance to immersion weathering.

\section{Compressive strength degradation}

Finally, the compressive strength degradation of the samples were monitored at periods throughout the experiment to determine the effect of the immersion weathering upon the mix types and the results are presented in Figure 4.5.

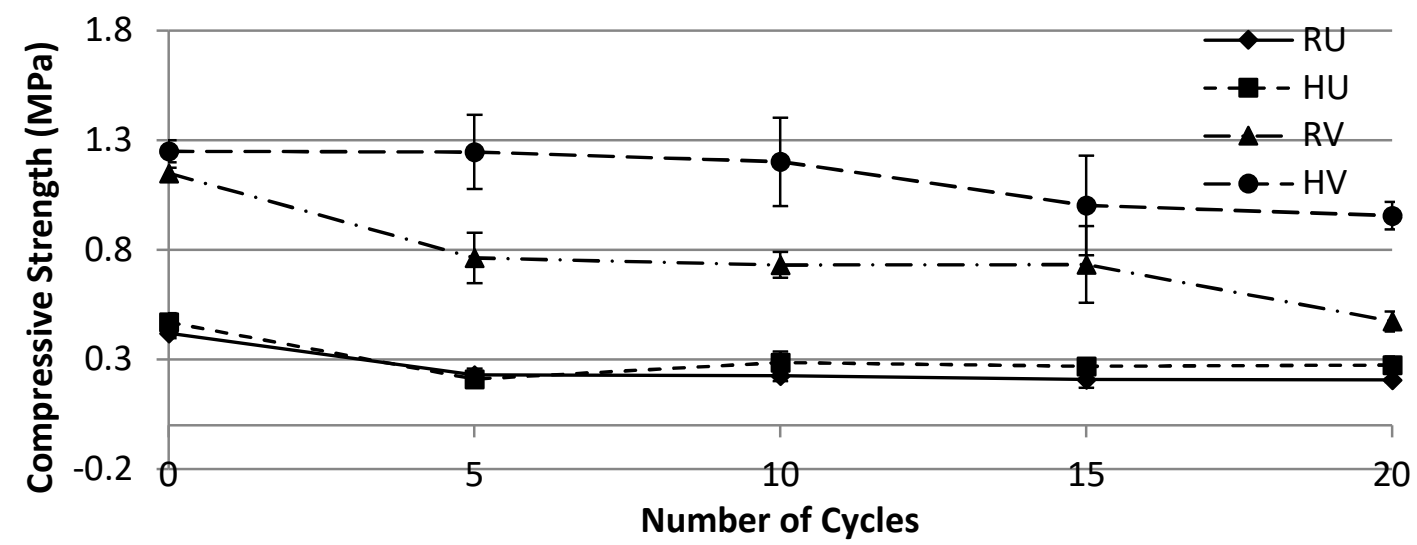

Figure 4.5 - Compressive strength development of concrete mixes during the immersion weathering test

The initially higher compressive strengths of the VMA samples are described by Sheridan et al. [23], but what is interesting with these results is the difference in strength degradation of the VMA and untreated samples. It can be seen that after 20 cycles, the compressive strength of the VMA 
samples is significantly reduced compared to the untreated samples. This is reflective of the mass gain results discussed in section 4.1.1 where the increase in mass gain of the untreated samples did not significantly increase, however for the VMA samples the mass gain progressively increased throughout the test. This is due to the weakening of the ITZ, propagation of cracks in the microstructure and increase in the material porosity.

The SEM images presented in Figure 4.3 in the previous section lead to the same explanation of the compressive strength degradation as the mass gain results. The washing away effect of the samples and the pore widening was a phenomenon that more severely affected the VMA samples because the ITZ of those samples had been improved so dramatically to start with. This meant that there was a much higher scope for damage (not including sample failure) and this is reflected in the compressive strength degradation results. It was observed that the VMA samples lost a larger amount of compressive strength both as a raw number and as a percentage in comparison with the untreated samples, yet ended up with a higher compressive strength (and better quality microstructure overall).

The standard deviation of the results is similar between all of the mixes; however, the results appear to be much more variable for the VMA samples. In reality, this is not the case, as the compressive strengths are also much higher when compared with the untreated samples. Hence, as a percentage the standard deviations are similar.

\subsection{Outdoor weathering}

In addition to the indoor simulation of weathering, samples were also left outside in natural conditions for a year and exposed to natural weathering. As stated in section 3.2 the testing was conducted in Belfast, Northern Ireland and the weather conditions for the year are presented in Table 3.1. The statistics presented are from the Met Office, the UK's national meteorological service, and is available freely online.

An important heading in Table 3.1 is the raindays category. This category records on average how many days of rainfall over $1 \mathrm{~mm}$ the weather stations around Belfast experienced. That is an important distinction from average rainfall because the two do not necessarily linearly correlate. It could be the case that in a given month every day could be considered a rainday, however only around $1 \mathrm{~mm}$ of rain falls per day, resulting in a total average rainfall for that month of 30 or $31 \mathrm{~mm}$ depending on the month. This would be considered very low for Northern Ireland. It is therefore a slightly more sophisticated view of the rainfall over a given month when viewed in conjunction with the average rainfall as it describes the concentration of rain over how many days in a given month. For example, if there is a high amount of rainfall but over only a few raindays the rain could be considered torrential 
while it is happening and thus potentially affect the exposed concrete samples differently to a lesser but more constant amount of rainfall.

After the year of exposure, the samples were dried according to the relevant drying step cycle length from the indoor weathering test and then were tested for compressive strength to see if the outdoor weathering had had any effect. The average compressive strength results are presented in Figure 4.6 against the control results after 28 days.

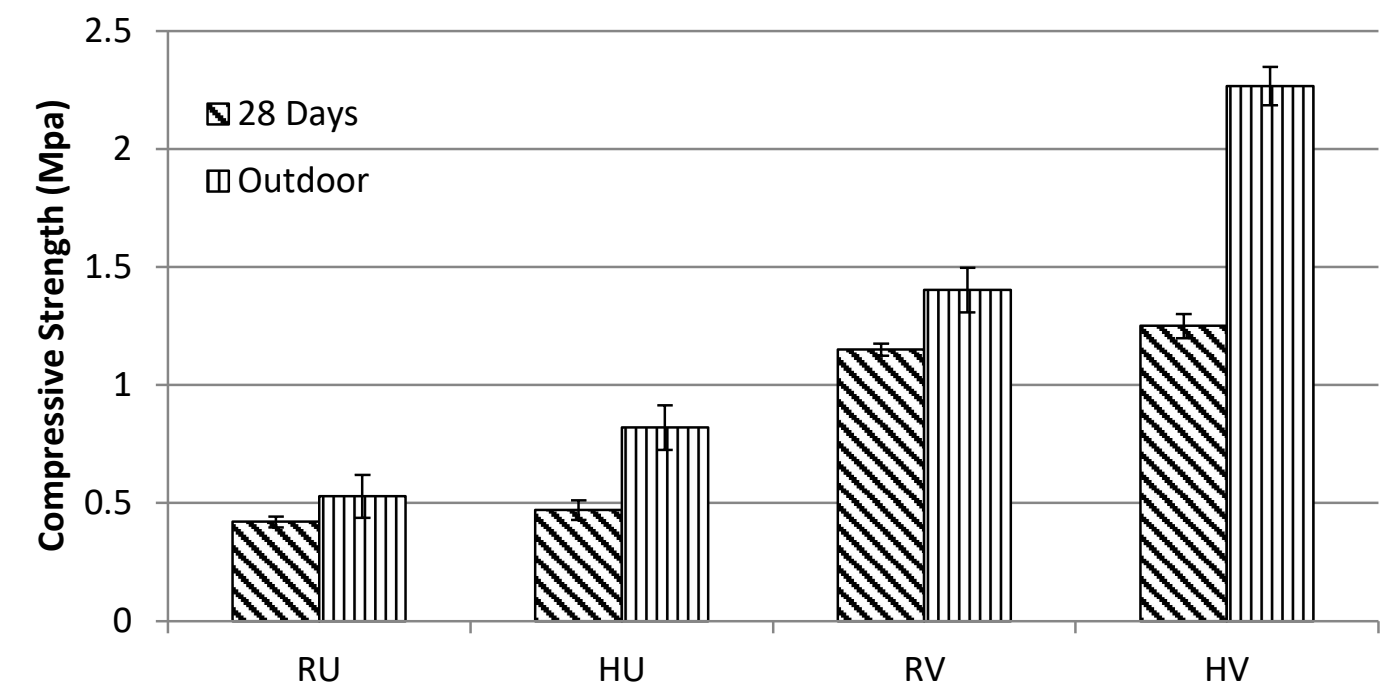

Figure 4.6 - Strength results from the outdoor weathering samples against the 28-day control sample results

As can be seen, the effect of the outdoor weathering did not degrade or indeed even inhibit the development of the compressive strength of the samples after a full year of exposure. This was probably due to the fact that over the year the samples could also have been carbonating; something that is being experimentally determined currently.

\subsection{Leaching}

\section{Introduction}

Leaching was studied in both the inorganic and organic phases. Results presented in section 4.1 lead to suspicions that cracks were propagating in the ITZ during the immersion weathering tests. These cracks occurred for different reasons but the main one was a "washing away" effect. Consequently, testing was conducted to conclude if this was the case. Because the bio-aggregates were made up of organic materials, some of them soluble, an experiment to investigate the organic leaching was also appropriate. The results of these experiments are presented in the following section. 
Inorganic leaching

Atomic absorption was used to identify calcium particles in the test water of the controlled immersion test. The results of this test are presented in Figure 4.7.

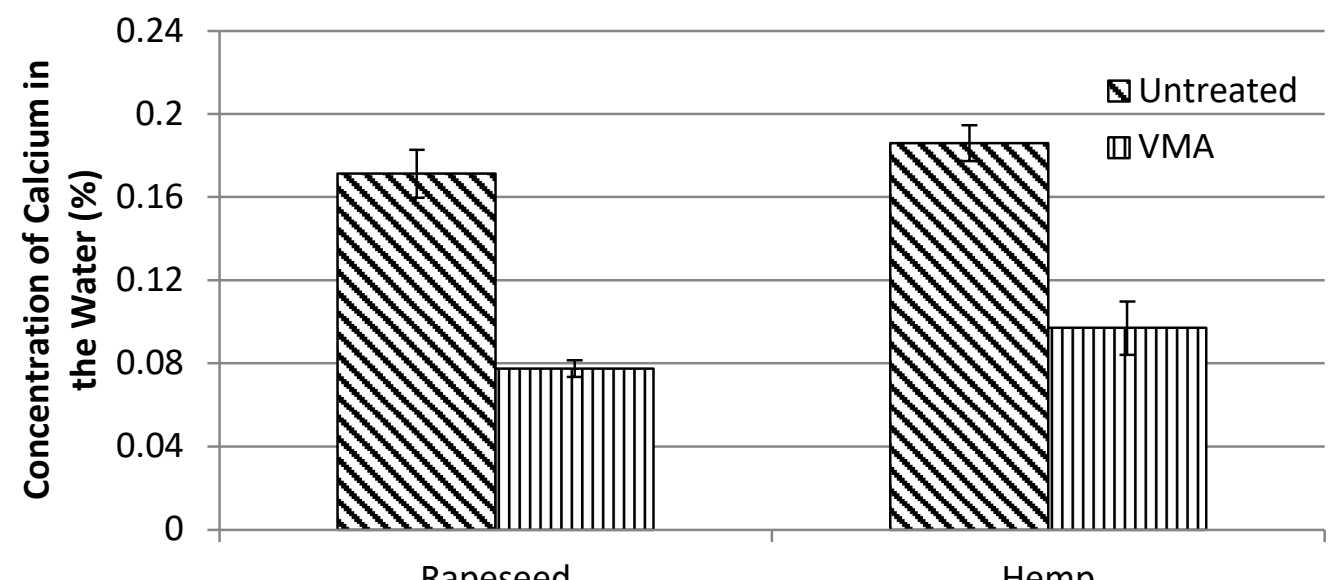

Rapeseed

Hemp

Figure 4.7 - Inorganic leaching of vegetal concretes

For reference the concentration of calcium in the tap water in south Belfast was reported as $0.00438 \%$ by Northern Ireland Water in 2018 [27]. Bearing in mind $d$ that this test was conducted on water that had been subjected to immersing samples for only 5 cycles; a much shorter test than the immersion weathering tests earlier in this investigation, it can be seen that there is clear evidence of mineral leaching. It can also be seen that the hemp samples suffered slightly greater mineral leaching than the rapeseed samples (42.5 times the amount of calcium found in Northern Irish water). In addition, it can be clearly seen that the addition of a VMA into the mix greatly reduced mineral leaching.

\section{Organic leaching}

Organic leaching was identified using FTIR which was conducted on samples of bio-aggregate removed from the crushed cubes after the compressive strength testing. Identifying all of the peaks on the spectra was a complicated process and the wavenumber values used to identify the peaks are tabulated below in Table 4.1 for simplicity, and the FTIR spectra are presented in Figure 4.7. The three 28-day control samples are denoted in Figure 4.8 as CTRL 1, CTRL 2 and CTRL 3 and the samples that were tested after 20 cycles in the immersion weathering test are denoted as WHU 1, WHU 2 and WHU 3. Again, for simplicity, the legend presented for the rapeseed untreated mix is the same for all other mixes. 
Table 4.1 - Description of main infrared absorption peaks for bio-aggregates

\begin{tabular}{|c|c|c|c|c|}
\hline $\begin{array}{l}\text { Wavenumber } \\
\left(\mathrm{cm}^{-1}\right)\end{array}$ & Bonding & Vibration Type & Material & Reference \\
\hline $3000-3600$ & $\mathrm{O}-\mathrm{H}$ & $\begin{array}{l}\text { Symmetric and } \\
\text { antisymmetric stretching }\end{array}$ & Polysaccharides & [28] \\
\hline $2850-2920$ & $\begin{array}{l}\mathrm{C}-\mathrm{H} \\
\left(\mathrm{CH}_{2}\right)\end{array}$ & $\begin{array}{l}\text { Antisymmetric } \\
\text { stretching }\end{array}$ & $\begin{array}{l}\text { Waxes, Lipids } \\
\text { and Fats }\end{array}$ & {$[29],[30]$} \\
\hline $1630-1650$ & $C=O$ & Symmetric stretching & Pectin & [28] \\
\hline $1505-1510$ & $\mathrm{C}=\mathrm{C}$ & Symmetric stretching & Lignin & {$[28],[29]$} \\
\hline 1425 & $\mathrm{CO}_{3}{ }^{2+}$ & $\begin{array}{l}\text { Antisymmetric } \\
\text { stretching }\end{array}$ & Calcite & [31] \\
\hline 1160 & $\mathrm{C}-\mathrm{O}-\mathrm{C}$ & $\begin{array}{l}\text { Antisymmetric } \\
\text { stretching }\end{array}$ & $\begin{array}{l}\text { Cellulose, } \\
\text { hemicelluloses }\end{array}$ & [28] \\
\hline 1030 & $\mathrm{C}-\mathrm{O}$ & Symmetric stretching & $\begin{array}{l}\text { Cellulose, } \\
\text { hemicelluloses }\end{array}$ & [32] \\
\hline 875 & $\mathrm{CO}_{3}{ }^{2+}$ & Symmetric bending & $\begin{array}{l}\text { Calcite } \\
\text { (Carbonate) }\end{array}$ & [31] \\
\hline
\end{tabular}

The first observation to notice in Figure 4.8 is that in all cases the peak from $3000-3600 \mathrm{~cm}$ ${ }^{1}$ in the weathered samples (denoted in black) has flattened out and is not as sharp as for the 28-day control samples (denoted in grey). This shows that during the immersion weathering testing the polysaccharides in the hemp and rapeseed aggregates were partially dissolved. In theory this makes sense as sugars are soluble, however this was not definitely expected.

Calcite peaks are also evidenced on the spectra at 875 and $1425 \mathrm{~cm}^{-1}$ and for all of the mixes are taller for the weathered samples in comparison with the control samples. This is to be expected as the weathered samples would have had around 9 months to carbonate naturally.

The hemicellulose and cellulose peaks at 1030 and $1160 \mathrm{~cm}^{-1}$ are interesting for all of the mixes aside from the hemp VMA mix. The peaks for the weathered hemp VMA mix have almost completely disappeared as expected because hemicellulose is a soluble sugar. However, for the other mixes the $1030 \mathrm{~cm}^{-1}$ peak consistently gets bigger and the $1160 \mathrm{~cm}^{-1}$ gets smaller. This can be simply explained because the peaks in both cases represent both cellulose and hemicellulose; hemicellulose is soluble however cellulose is insoluble. Thus, the peculiar change in peak shape was due to the change in quantity of the two materials before and after testing. It is believed that the removal of the 
hemicellulose caused the reduction in the peak and the minor increase in the $1030 \mathrm{~cm}^{-1}$ peak was due to the resulting increased concentration of cellulose.

Changes in lignin quantity are relatively hard to observe for the mixes because the lignin peak is so close to the large and asymmetric calcite peak. However, for all mixes it is still possible when comparing the control spectra to the weathered spectra. In all cases aside from the third control sample (CTRL 3) for the rapeseed untreated mix a shoulder is observed around $1505 \mathrm{~cm}^{-1}$, which is the lignin peak. When looking at the weathered spectra the shoulder has disappeared. In some cases it is harder to see because the calcite peak is asymmetric [31]. However, the shape of the peak is clearly different when comparing the samples before and after the test. Thus, it can be concluded for all mixes that immersion weathering also results in the dissolution of lignin.

The next peak along the spectra is the pectin peak at $1630-1650 \mathrm{~cm}^{-1}$. The changes in this peak can be described as inconsistent, especially for the rapeseed aggregate. The peak was consistently lowered for both of the hemp samples; however, it was not completely removed for either. This is a positive result for the hemp mixes as pectin was the sugar that was identified as a problematic constituent part due to its tendency of trapping calcium ions from the binder and retarding long-term strength [21], [22]. Hence the removal of the pectin theoretically means better long-term strength development. The results for the rapeseed samples are less consistent, with evidence of a diminished pectin peak in some weathered samples, and no observed effect in others. One explanation for this could be (as with the waxes in the next paragraph) that pectins are predominantly found in the epidermis of the plant cell [33], so there does seem to be evidence of pectin dissolution in the rapeseed sample results however the inconsistency is brought about by the fact that the sugar is not omnipresent throughout the samples as a whole.

The last peak to be studied is the peak from $2850-2920 \mathrm{~cm}^{-1}$, which is representative of any waxes, lipids and fats in the aggregate. This was the second discrepancy between the two aggregates because the waxes and fats are dissolved once again in both of the hemp samples. In contrast, again no effect was noted when looking at the rapeseed samples. It should be noted that the waxes and fats peak on the hemp samples is only minor and is not consistently present. This, as with pectin, may suggest an explanation as to why they are seemingly removed. It may be the case that they simply were not present in the weathered samples as the waxes, lipids and fats are only found in the epidermis of the straw anyway, whereas the other constituent parts are omnipresent throughout the stem. The peaks are more clearly present for the rapeseed samples however; their lack of dissolution could again be explained by their rarity in the cross-section of the stem. Alternatively, it could be the case that the immersion weathering test had no effect in dissolving them. 

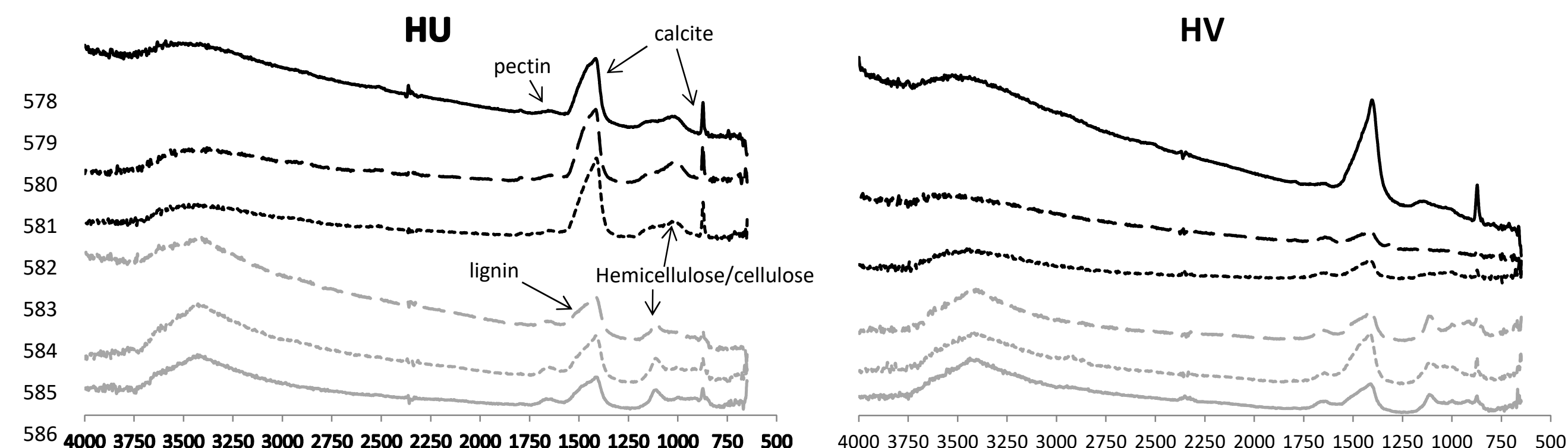

587
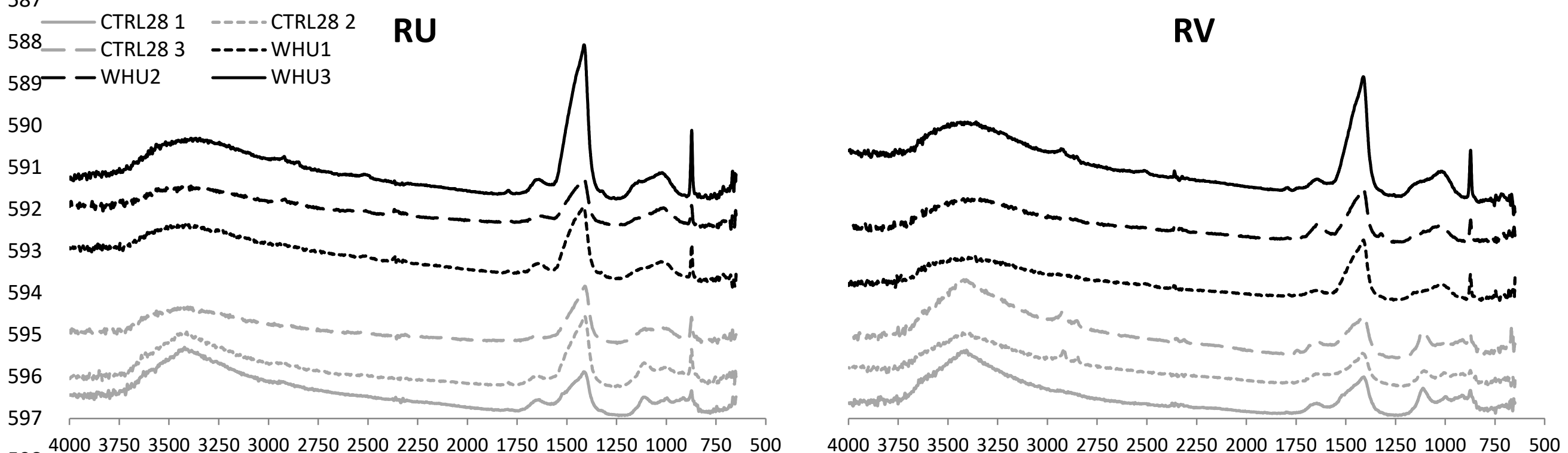

Figure 4.8 - FTIR data for all mixes before and after the immersion weathering test 
There are similar FTIR studies conducted on surface treatments of lignocellulosic aggregates that demonstrate the effects of alkaline substances on the dissolution or removal of certain organic constituent elements of the aggregates. Nozahic and Amziane and Chabannes et al. [34], [35] both found that treating lignocellulosic aggregates with lime water (aqueous calcium hydroxide) resulted in the removal of hemicelluloses, lignins, polysaccharides and to a certain extent, pectins, as did this study. However, these studies were conducted with a purposeful treatment of the aggregates with an alkaline solution; this study was with water only.

These results could have an impact on the real-world application of vegetal concretes, especially exposed vegetal concretes as these sugars are known to inhibit strength development. Thus, the removal of sugars with water can only be considered as a significant improvement for the development of their long-term strength. However, caution must be taken with these results, as it may be the case that it was a basic solution removing these organics due to the fact that, as has been

612 demonstrated in section 4.2.2, calcium was leaching into the test water as the experiment progressed.

613 This slow leaching of calcium could have increased the $\mathrm{pH}$ of the test water and been responsible for 614 the observed results, creating a similar test to the ones conducted by Nozahic and Amziane and 615 Chabannes et al. [34], [35].

To determine if the dissolution and removal of the organics for the full immersion test was a consequence of the test water only or the test water and the added calcium from the inorganic leaching, FTIR was conducted on the samples that were weathered under natural conditions outside. Again, as with the immersion weathering FTIR results the control samples tested at 28 days are denoted in grey and the weathered samples are denoted in black. For simplicity the legend presented in the hemp VMA spectra is the same legend as was used for the rest of the mixes. 
HU

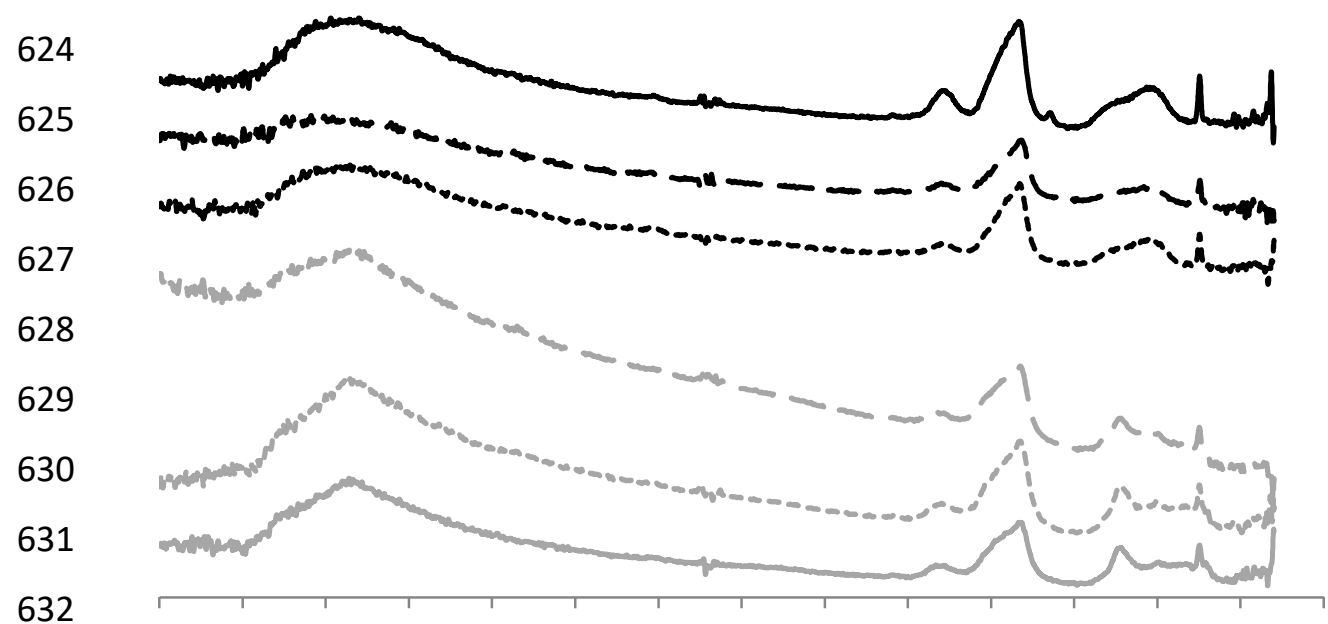

4000375035003250300027502500225020001750150012501000750500

RU

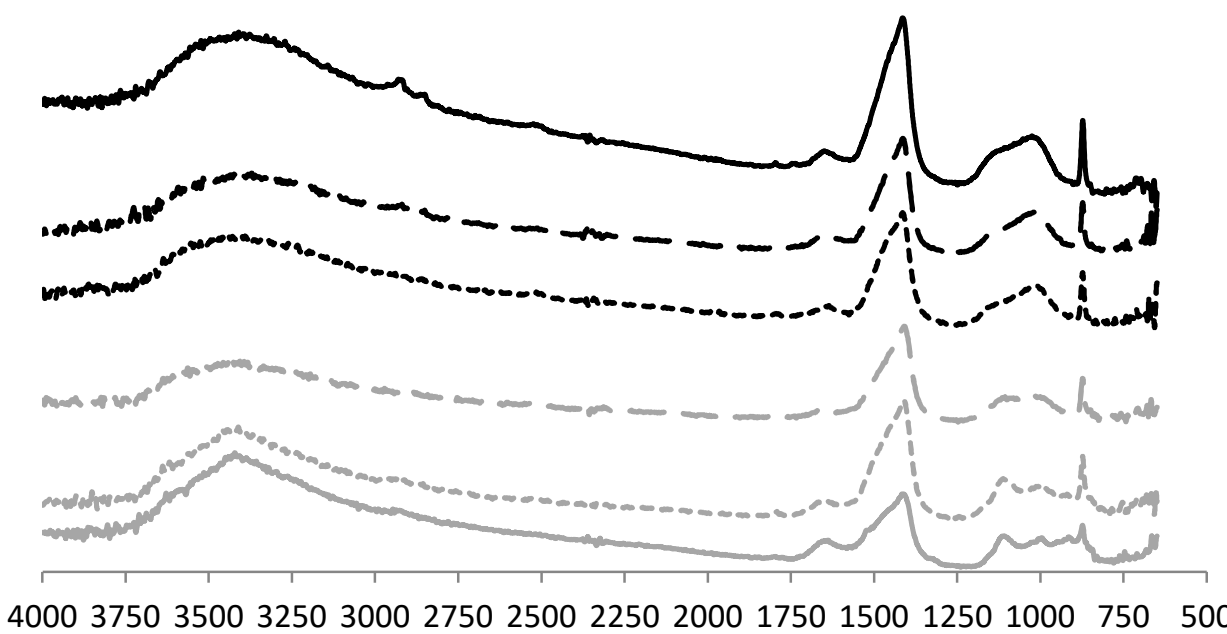

HV

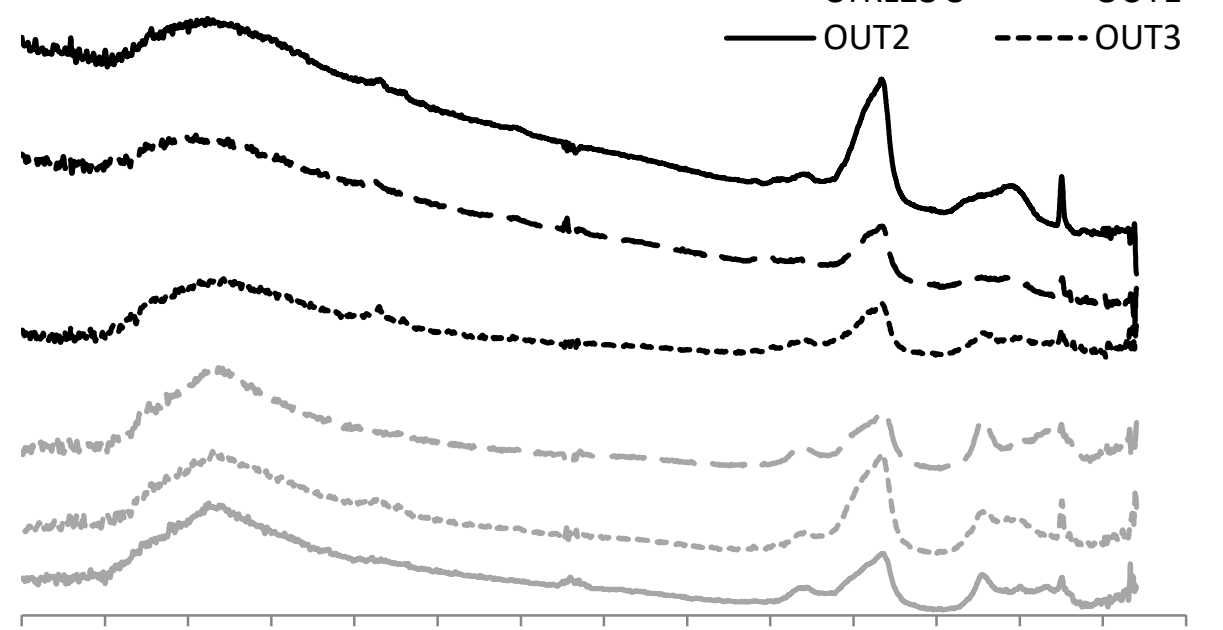

4000375035003250300027502500225020001750150012501000750500

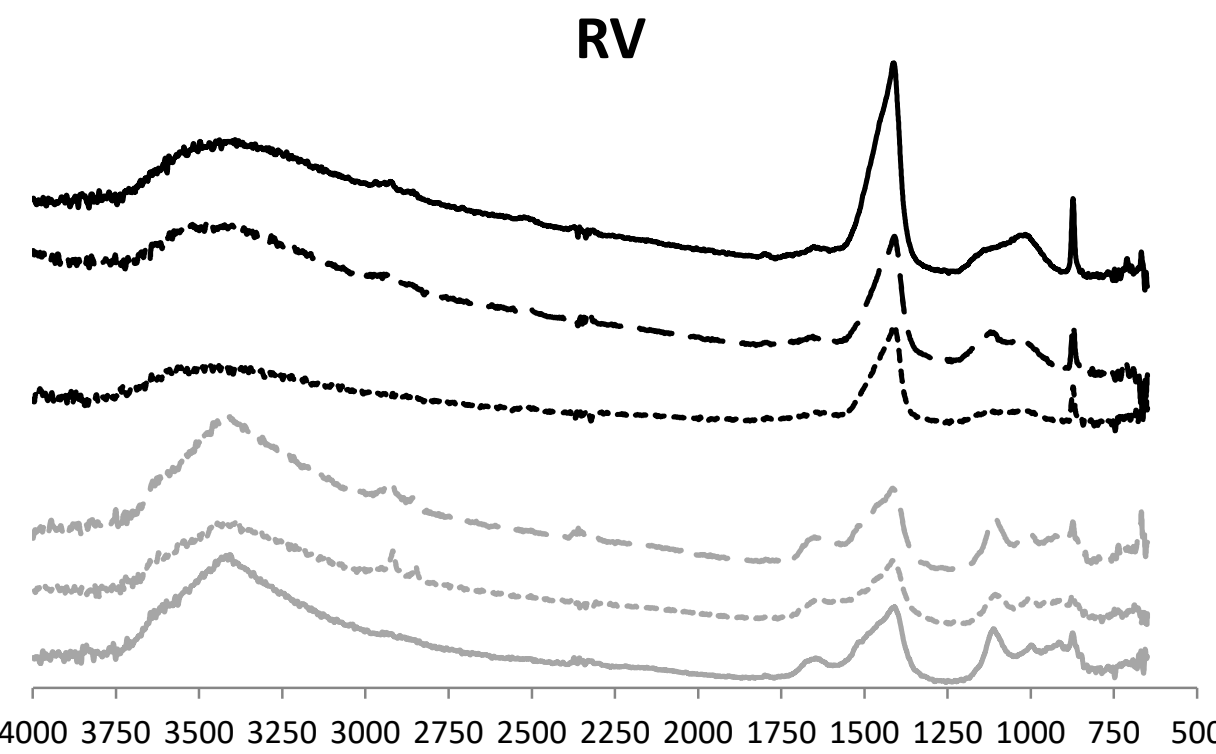


The outdoor weathering samples follow much the same trends as found in the indoor immersion weathering FTIR results and the literature [34], [35]; in all cases the naturally weathered samples exhibit a partial removal of polysaccharides $\left(3000-3600 \mathrm{~cm}^{-1}\right.$, dissolution of hemicelluloses and re-concentration of the insoluble cellulose (1030 and $1160 \mathrm{~cm}^{-1}$ ), the dissolution of lignin (around $\left.1505 \mathrm{~cm}^{-1}\right)$, the partial and inconsistent removal of pectin $\left(1630-1650 \mathrm{~cm}^{-1}\right)$ and waxes, fats and lipids $\left(1850-2920 \mathrm{~cm}^{-1}\right)$.

The results are actually remarkably similar to those of the immersion weathering test; implying that only a wet climate is needed to effect these changes and not an extreme test of full immersion over the course of 9 months. This confirms the positive conclusion made in the previous section that water only is needed to remove sugars in these bio-aggregates which, in the case of pectin, is positive for vegetal concretes.

657

\section{Conclusions}

Overall, it can be concluded that hemp concretes are slightly more durable regarding immersion weathering compared to rapeseed concretes. This was because over time and with increased exposure to the immersion weathering it was observed that the rapeseed samples suffered more damage to the binder matrix and so absorbed more mass by water. Although, both concrete types can be described as being highly susceptible and both lost compressive strength as the experiment progressed. Finally, the addition of a VMA increases the durability of both concrete types regarding long term immersion weathering. Although again, with time the resistance of VMA concretes to immersion weathering begins to break down.

Outdoor weathering was also conducted and no effect was imparted on the samples, indeed the compressive strength increased. This was probably because the samples would have been carbonating naturally in the outdoor environment (although this was not investigated and so at this point is a hypothesis only), providing an increase in strength and the ability to overcome the negative effect on compressive strength imparted by the weathering. over a condensed test compared to the immersion weathering test, large amounts of calcium were found in the testing water after 5 weathering samples. The highest concentration was found in the untreated hemp samples, the water of which averaged $0.186 \%, 42.5$ times the calcium content of water in South Belfast, Northern Ireland [27]. leaching more than the rapeseed samples for both the untreated and VMA samples, but this difference was considered negligible. What was noticeable, however, was the effect of adding a VMA 
into the mix, which greatly reduced the amount of inorganic leaching. This is a positive effect, as its ability to restrict the leaching of calcium during immersion weathering could result in an overall increase in long term strength development.

Organic leaching gave a strong indication that most of the soluble constituent parts in lignocellulosic materials did indeed dissolve. FTIR results revealed that polysaccharides partially dissolved for all hemp and rapeseed mixes, so too did hemicelluloses and lignin. Pectin also dissolved, although not fully, and as this peak was identified as a retarding agent on the setting of cementitious materials, future work is needed to identify a process to remove this material completely.

It was also observed that the results for pectin and lipids, fats and waxes were inconsistent for all mixes, however this was due to the fact that these organics are not omnipresent throughout the aggregates as a whole. Their presence was solely due to where the FTIR was conducted on the aggregate sample. If the technique was conducted on the epidermis of an aggregate particle, evidence was found of their dissolution; however, if the test was conducted anywhere else there was much less evidence of their presence due to the reduced concentration of pectin in other parts of the stem.

\section{Acknowledgements}

The authors would like to acknowledge Vicat for supplying the binder in this investigation and Larsen Building Products for supplying the VMA admixture.

\section{References}

[1] E. Fehling, M. Schmidt, and S. Sturwald, "Ultra High Performance Concrete (UHPC)," in Second International Symposium on Ultra High Performance Concrete, 2008, p. 136.

[2] The Cement Sustainability Initiative, "The Cement Sustainability Initiative: 10 years of progress - moving on to the next decade," p. 32, 2012.

[3] V. M. Malhotra, "Sustainability and Concrete Technology," 2004.

[4] J. Davidovits, "Global Warming Impact on the Cement and Aggregates Industries," World Resource Review, vol. 6, no. 2, pp. 263-278, 1994.

[5] International Energy Agency, "Cement: Tracking Clean Energy Progress," 2018. [Online]. Available: https://www.iea.org/tcep/industry/cement/. [Accessed: 11-Jan-2019].

[6] Eurostat, "Energy statistics - an overview," 2018. [Online]. Available: https://ec.europa.eu/eurostat/statistics-explained/index.php?title=Energy_statistics__an_overview\#Final_energy_consumption. [Accessed: 11-Jan-2019].

[7] J. (DECC) Palmer and I. (DECC) Cooper, "Housing Energy Fact File," Department of Energy \& Climate Change, p. 171, 2013. 
[8] S. Marceau, P. Glé, M. Gueguen, E. Gourlay, S. Moscardelli, I. Nour, S. Amziane, and L. Abdellaoui, "Assessment of the durability of bio-based insulating materials," in First International Conference on Bio-based Building Materials, 2015, pp. 198-202.

[9] P. Hellebois, S. Marceau, M. Gueguen, and S. Amziane, "Influence of wetting and drying cycles on the properties of hemp concrete," in 1st International RILEM Conference on Rheology and Processing of Construction Materials, 2013.

[10] A. Grelat, "Using sustainable materials as walling for individual housing with wood structure Final report extracts Volume 2 - Laboratory experiments Site instrumentation," 2004.

[11] G. Delannoy, S. Marceau, P. Glé, E. Gourlay, M. Gueguen-Minerbe, S. Amziane, and F. Farcas, "Evolution of Hemp Concrete Properties Exposed to Different Types of Environments," in Synercrete' 18 International Comnference on Interdisciplinary Approaches for Cement-based Materials and Structural Concrete, 2018, pp. 505-510.

[12] M. Chabannes, E. Garcia-Diaz, L. Clerc, and J. C. Bénézet, "Studying the hardening and mechanical performances of rice husk and hemp-based building materials cured under natural and accelerated carbonation," Construction and Building Materials, vol. 94, pp. 105-115, 2015.

[13] C. Sentenac, M. Sonebi, and S. Amziane, "Investigation on the Performance and Durability of Treated hemp Concrete with Water Repellent," in 2nd International Conference on Bio-based Building Materials, 2017, pp. 489-497.

[14] R. Walker, S. Pavía, and R. Mitchell, "Mechanical properties and durability of hemp-lime concretes," Construction and Building Materials, vol. 61, pp. 340-348, 2014.

[15] P. Hellebois, "Etude de l'évolution des propriétés des bétons de chanvre pendant leur vieillissement," Polytech Clermont-Ferrand - Université Clermont Auvergne, 2013.

[16] M. Sonebi, S. Wana, S. Amziane, and J. Khatib, "Investigation of the mechanical performance and weathering of hemp concrete," in First International Conference on Bio-based Building Materials, 2015, pp. 416-421.

[17] C. Yoann, S. Amziane, and M. Sonebi, "Investigation of Weathering Resistance of Hemp Concrete," in Proceedings of first Int. Conf. on Construction Materials for Sustainable Future, 2017.

[18] C. Sentenac, M. Sonebi, and S. Amziane, "Investigation on the Performance and Durability of Treated Hemp Concrete with Linseed Oil," in 2nd International Conference on Bio-based Building Materials, 2017, pp. 343-351.

[19] C. Magniont and G. Escadeillas, "Chemical Composition of Bio-aggregates and Their Interactions with Mineral Binders," in Bio-aggregates Based Building Materials; State-of-theArt Report of the RILEM Technical Committee 236-BBM, S. Amziane and F. Collet, Eds. Springer, 
2017, pp. 1-38.

[20] Y. Diquélou, E. Gourlay, L. Arnaud, and B. Kurek, "Impact of hemp shiv on cement setting and hardening: Influence of the extracted components from the aggregates and study of the interfaces with the inorganic matrix," Cement and Concrete Composites, vol. 55, pp. 112-121, 2015.

[21] D. Sedan, C. Pagnoux, T. Chotard, A. Smith, D. Lejolly, V. Gloaguen, and P. Krausz, "Effect of calcium rich and alkaline solutions on the chemical behaviour of hemp fibres," Journal of Materials Science, vol. 42, no. 22, pp. 9336-9342, 2007.

[22] D. Sedan, C. Pagnoux, A. Smith, and T. Chotard, "Mechanical properties of hemp fibre reinforced cement : Influence of the fibre / matrix interaction," vol. 28, pp. 183-192, 2008.

[23] J. Sheridan, M. Sonebi, S. Taylor, and S. Amziane, "The effect of a polyacrylic acid viscosity modifying agent on the mechanical, thermal and transport properties of hemp and rapeseed straw concrete," Construction and Building Materials, vol. 235, 2020.

[24] SEBTP, "Construire en Chanvre, règles professionnelles d'exécution de construction," 2012.

[25] Met Office, "UK and regional series," 2019. [Online]. Available: https://www.metoffice.gov.uk/climate/uk/summaries/datasets\#yearOrdered. [Accessed: 09Jan-2019].

[26] J. Sheridan, "The Long Term Durability Performance and Water Sensitivity of Vegetal Concrete," 2019.

[27] Northern Ireland Water, "About your water - Water Quality Results," 2018. [Online]. Available: https://www.niwater.com/water-quality-results.aspx. [Accessed: 23-Jan-2019].

[28] M. Le Troëdec, C. Peyratout, T. Chotard, J. P. Bonnet, A. Smith, and R. Guinebretiere, "Physicochemical modifications of the interactions between hemp fibres and a lime mineral matrix: impacts on mechanical properties of mortars," in 10th International Conference of the European Ceramic Society, 2007, pp. 451-456.

[29] V. Tserki, P. Matzinos, and C. Panayiotou, "Novel biodegradable composites based on treated lignocellulosic waste flour as filler Part II . Development of biodegradable composites using treated and compatibilized waste flour," Composites Part A: Applied Science and Manufacturing, vol. 37, pp. 1231-1238, 2006.

[30] V. Nozahic, "Vers une nouvelle démarche de conception des bétons de végétaux lignocellulosiques basée sur la compréhension et I' amélioration de l' interface liant / végétal : application à des granulats de chenevotte et de tige de tournesol associés à un liant ponc," 2012.

[31] D. A. Silva, H. R. Wenk, and P. J. M. Monteiro, "Comparative investigation of mortars from 
Roman Colosseum and cistern," Thermochimica Acta, vol. 438, pp. 35-40, 2005.

[32] W. Nakbanpote, B. A. Goodman, and P. Thiravetyan, "Copper adsorption on rice husk derived materials studied by EPR and FTIR," Colloids and Surfaces A: Physicochemical and Engineering Aspects, vol. 304, no. 1-3, pp. 7-13, 2007.

[33] A. Jauneau, M. Quentin, A. Driouich, L. Parois, S. C. Universit, and E. Organismes, "Microheterogeneity of pectins and calcium distribution in the epidermal and cortical parenchyma cell walls of flax hypocotyl," Protoplasma, vol. 198, pp. 9-19, 1997.

[34] V. Nozahic and S. Amziane, "Influence of sunflower aggregates surface treatments on physical properties and adhesion with a mineral binder," Composites Part A: Applied Science and Manufacturing, vol. 43, no. 11, pp. 1837-1849, 2012.

[35] M. Chabannes, E. Garcia-Diaz, L. Clerc, and J. C. Bénézet, "Effect of curing conditions and $\mathrm{Ca}(\mathrm{OH}) 2$-treated aggregates on mechanical properties of rice husk and hemp concretes using a lime-based binder," Construction and Building Materials, vol. 102, pp. 821-833, 2016. 